\title{
Predicting Of Machining Quality In Electric Discharge Machining Using INTELLIGENT OPTIMIZATION TECHNIQUES
}

\author{
Dragan Rodic ${ }^{1}$, Marin Gostimirovic ${ }^{1}$, Pavel Kovac ${ }^{1}$, Ildiko Mankova ${ }^{2}$ and \\ Vladimir Pucovsky ${ }^{1}$ \\ ${ }^{1}$ University of Novi Sad, Faculty of Technical Sciences, Institute for Production \\ Engineering, Trg Dositeja Obradovica 6, 21000 Novi Sad, Serbia \\ rodicdrduns.ac.rs; maring@uns.ac.rs; pkovacduns.ac.rs; \\ pucovski@uns.ac.rs \\ ${ }^{2}$ Technical University of Košice, Department of Technology and Materials, Faculty of \\ Mechanical Engineering, Masiarska, 04001 Kosice 74, Slovakia \\ Ildiko.Mankova@tuke.sk
}

\begin{abstract}
This paper presents the development and application of fuzzy logic, neural network and genetic algorithm in EDM (Electrical Discharge Machining) for prediction of machining quality. Machining quality is the main indicator of technological performances of a component for EDM. The experiments are carried out on manganese alloyed cold-work tool steel, processed with electrodes made of copper. Experiments were conducted by varying the discharge current and pulse duration and the corresponding values of surface roughness were measured. The values of machining quality predicted by these models are then compared. All models show good agreement with experimental results. The results indicate that the genetic programming technique gives slightly smaller deviation of the measured values of model than fuzzy logic and neural network.
\end{abstract}

\section{KEYWORDS}

EDM, machining quality, fuzzy logic, neural network, genetic programming

\section{INTRODUCTION}

The quality of finished products is defined by how closely the finished product adheres to certain specifications, including dimensions and surface quality. Surface quality is defined and identified by the combination of surface finish, surface texture, and surface roughness. Surface roughness $\left(R_{a}\right)$ is the commonest index for determining surface quality [1,2].

EDM process do not allow achieving the theoretical surface roughness due to defects appearing on machined surfaces and mainly generated by deficiencies and imbalances in the process. Due to these aspects, measuring procedures are necessary; as it permits one to establish the real state of surfaces to manufacture parts with higher accuracy. To know the surface quality, it is necessary to employ theoretical models making it feasible to do predictions in function of response parameters [3]. In this paper three methods of EDM process modelling are investigated: neuro-fuzzy system, neural network and genetic programming. 
Recently, some initial investigations in applying the basic artificial intelligence approach to model machining processes. To generalize the experimental results and develop the system model accurately, neural networks and fuzzy systems are reported as an alternative approach $[4,5]$. Wang et al. [6] development and application of a hybrid artificial neural network and genetic algorithm methodology to modelling and optimisation of electro-discharge machining. An adaptive neuro-fuzzy inference system (ANFIS) model has been developed for the prediction of the white layer thickness (WLT) and the average surface roughness achieved as a function of the process parameters by Çaydas [7]. Yilmaz et al. [8] presented a intelligent system for the selection of electro discharge machining parameters which lead to less electrode wear, better surface quality and more erosion rate according to the selected operation (finishing, roughing, etc.). Rao et al. [9] developed mathematical model for predicting die-sinking electrical discharge machining of aluminium alloy characteristics such as the metal removal rate (MRR), the tool wear rate (TWR), the surface roughness $\left(R_{a}\right.$ value) and the hardness (HRB) using fuzzy mathematical method. Multi-objective optimisation of electrical discharge machining of metal matrix composite using non-dominated sorting genetic algorithm were explained by Golshan et al. [10]. In this research, the influence of electrical discharge machining (EDM) on surface roughness and material removal rate (MRR) in metal matrix composite was investigated. Kuriakose et al. [11] presented work, a multiple regression model is used to represent relationship between input and output variables and a multi-objective optimization method based on genetic algorithm is used to optimize Wire-EDM process. As mentioned above, many researchers studied to find the relationships between input and output parameters in EDM process by using intelligent optimization techniques.

From the review of literature, it is observed that artificial intelligence techniques including neurofuzzy system, neural network and genetic algorithm have found wide applications in modelling of process parameters and controlling the EDM system components.

However, a comprehensive study to compare the performances of intelligent optimization techniques for modelling of machining quality in EDM is still missing. In this study, discharge current and pulse duration as machining conditions were selected. A neuro-fuzzy, neural network and genetic programming models were developed and compared using these machining parameters.

The paper gives a short overview of modelling approaches frequently used in manufacturing with emphasis on the workpiece quality. Contribution of this paper is that not only modelling is done by neuro-fuzzy system, neural network and genetic programming, but comparison of three modelling methodologies. Comparative observation showed that the genetic programming gives slightly smaller deviation of the measured values of model than neuro-fuzzy model.

\section{DESIGN OF EXPERIMENTS}

Evolutionary Experimental investigation was conducted on an EDM machine tool "FUMEC CNC 21" in South Korea. The work material used in the experiment was manganese-vanadium tool steel, ASTM A681 (0,9\% C, 2\% Mn, and 0,2\% V), hardness $62 \mathrm{HRc}$. The tool was made of electrolytic copper with $99,9 \%$ purity and $20 \times 10 \mathrm{~mm}$ cross-section. The dielectric was petroleum. Due to small eroding surface and depth, natural flushing was used.

The machining conditions included variable discharge current and pulse duration. The range of the discharge current was $\mathrm{I}_{\mathrm{e}}=1 \div 50 \mathrm{~A}$ (current density $0,5 \div 25 \mathrm{~A} / \mathrm{cm} 2$ ), while the pulse duration was chosen from the interval ti=1 $\div 100 \mu$ s to accommodate the chosen current. The rest of the parameters of electric impulse were held constant, according to the manufacturer's recommendations (open gap voltage $\mathrm{U}_{\mathrm{o}}=100 \mathrm{~V}$, duty factor $\tau=0,8$ and positive tool electrode 
polarity).The experiments were conducted according to the specified experiment plan. Input parameters were varied and the resulting machining parameters of EDM process were monitored and recorded. Measured parameter was surface roughness $\mathrm{R}_{\mathrm{a}}$. Surface integrity was assessed by measuring surface roughness and research of the surface layer properties. "PERTHOMETER S5P" of Mahr, Germany was used to measure the arithmetic average deviation of the assessed profile (ISO 4287) [12].

\section{AdAPTIVE NEURO-FuZZY INFERENCE SySTEM (ANFIS)}

The acronym ANFIS derives its name from adaptive neuro-fuzzy inference system. Fuzzy inference system (FIS) is a rule based system consisting of three components. These are:

- a rule-base, containing fuzzy if-then rules,

- a data-base, defining the Membership Functions (MF) and

- an inference system that combines the fuzzy rules and produces the system results.

Using a given input/output data set, the ANFIS method constructs a fuzzy inference system (FIS) whose membership function parameters are tuned (adjusted) using either a back propagation algorithm alone, or in combination with a least squares type of method. Figure 1 shows the flowchart for predicting the surface roughness via ANFIS. The process followed in this study is illustrated in Figure 1.

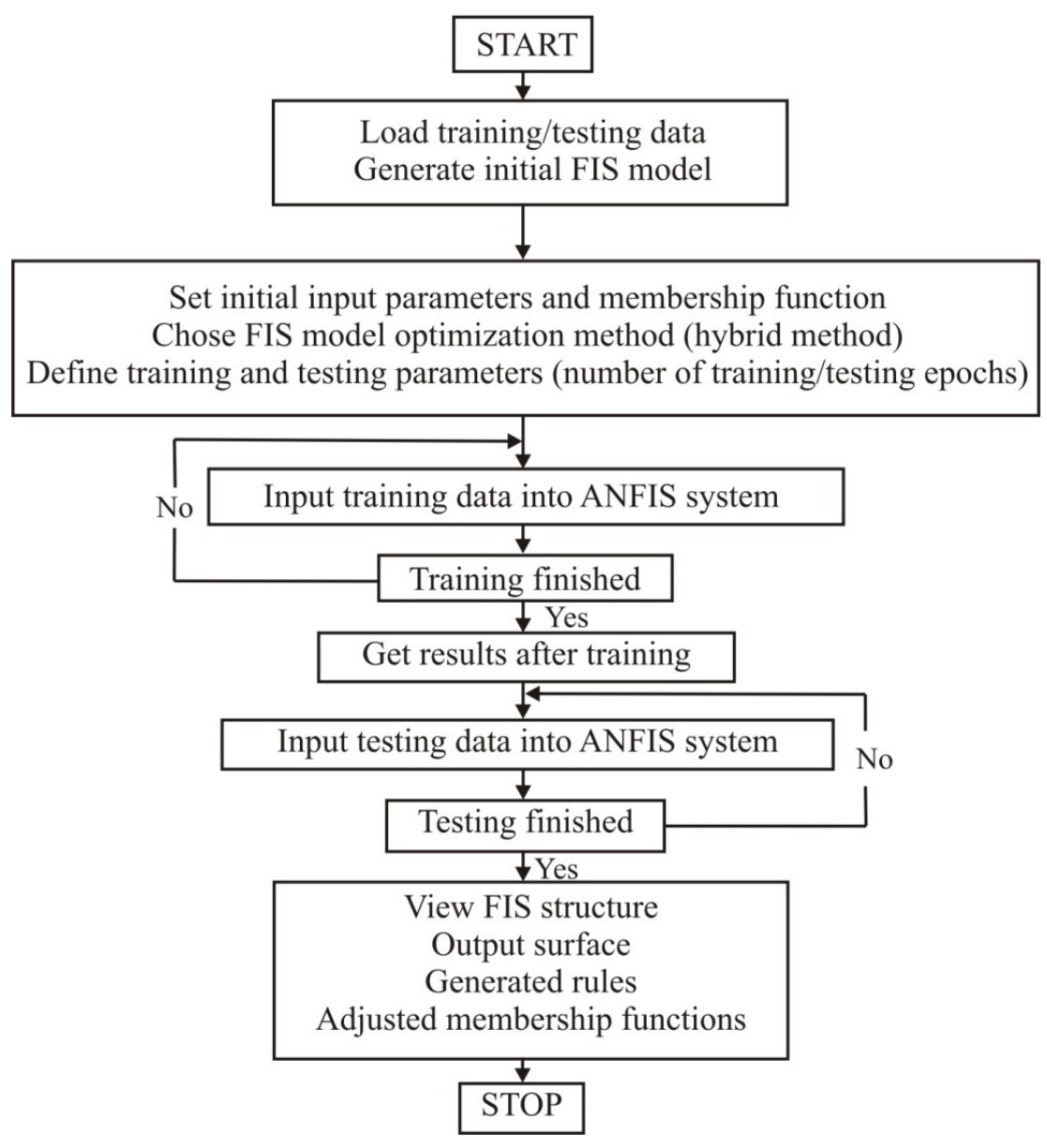

Figure 1. Flowchart of surface roughness prediction of ANFIS system [13] 
For this model, main parameters for the experiments are discharge current $I_{e}$, pulse duration $t_{i}$ (input data set) and surface roughness $\mathrm{R}_{\mathrm{a}}$ (output data set) (Figure 2). The training dataset and testing dataset are obtained from experiments. The input/output dataset was divided randomly into three categories: training dataset, consisting 18 of the input/output dataset, checking dataset, consisting 5 of the data and validation (unknown to model) data set, which consists 5 of data.

Training process is accomplished by using Mat Lab 6.0. In order to determine the optimal network architecture, various network architectures were designed; different training algorithms were used. The number and type of membership functions, method optimization hybrid or back propagation, and number epoch were changed. Then the best adaptive network architecture was determined. The training epoch for each network is 500, hybrid method optimization, the best results given three membership functions Gaussian type. When the network training was successfully finished, the ANFIS was tested with validation data.

\section{Layer 1 Layer 2 Layer 3 Layer 4 Layer 5}

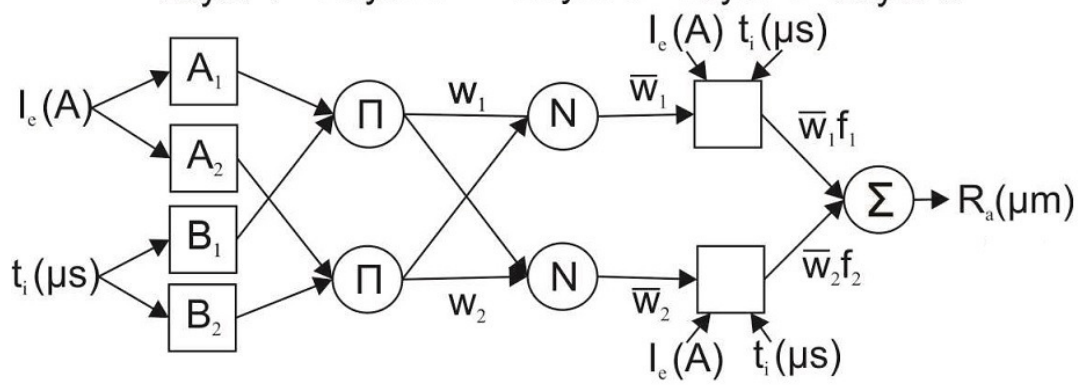

Figure 2. Basic ANFIS architecture

\section{Genetic Programming (GP)}

Evolutionary algorithms, with genetic programming being a subclass, as their name is suggesting are based on principles of evolution and natural selection. Each solution to the problem is considered to be one individual which is evaluated by fitness function. Results of evaluation are directly determining each individual's probability of mating and thus transferring his genetic material onto next generation.

Fitness function which will be used to evaluate quality of generated solution is mean square error function:

$$
\Delta=\frac{1}{28} \sum_{i=1}^{28}(P(i)-D(i))^{2}
$$

where $\mathrm{P}$ is experimentally obtained value and $\mathrm{D}$ is modeled value for every parameter.

For practical realization of model software GPdotNET was used [14]. At the beginning six random constants were generated from the interval $0 \div 10$. These will be used in equations forming as supporting members. Not to be confused, those constants don't have to be in final solutions. They are just available there for algorithm to use them. Sometimes solutions are found to be better without some constants. Number of individuals in every generation was 500. Elite count was 16, which means that from every generation 16 individuals with best fitness were automatically moved to next generation. Whole modeling procedure lasted for 500 generation. During that time evolution operators were executed with probabilities: 0,7 for crossover to 
happen, mutation $0,1,0,2$ for reproduction and 0,05 for permutation. Only arithmetic operators, respectively “+”, “-“, “*” and "””, are used to form membership functions.

\section{Artificial Neural Network (AnN)}

The basic architecture of a Neural Network typically consists of an input function, which can take the form of binary, continuous or normalized data: a processing architecture which consist of transfer function description, summation function, and relative learning strategy: a method for identifying and learning from past errors in estimates: and finally a mechanism for feeding error corrections back into the network [15].

A multilayer feed-forward network has been used, and the backpropagation training algorithm has been employed to train the network. Backpropagation is a systematic method for training multilayer ANN. A backpropagation network is a multilayer feed-forward network which uses gradient-descent method to minimize the total squared error of the output computed by the net. The training algorithm of back-propagation involves four stages which are initialization of weights, feed-forward, backpropagation of errors, and updating the weights and biases [16].

Modeling of the EDM with feed forward neural network is composed of two stages: training and testing of the network with experimental machining data. The scale of the input and output data is an important matter to consider, especially when the operating ranges of process parameters are different. The scaling or normalization ensures that the ANN will be trained effectively without any particular variable skewing the results significantly. As a result, all the input parameters are equally important in the training of network.

The architecture of the designed network comprises two input neurons corresponding to two input parameters, an output layer with one neuron corresponding to one output parameter at a time, and a single hidden layer of neurons. The transfer functions which have been used are tansig and purelin in hidden and output layers, respectively. The transfer function tansig is a hyperbolic tangent sigmoid transfer function, and purelin is a linear transfer function. With the help of back propagation training data set (Input parameters related to output parameters) is set to utilize to train the neural network. Two input parameters and one output parameter are considered. The selected input parameters should be easily variable and can be easily changed by the operator.

- Selected input parameters are: discharge current $I_{e}(A)$ and pulse duration $t_{i}(\mu \mathrm{m})$

- Selected output parameter is: Surface roughness $R_{a}(\mu \mathrm{m})$

A good number of experiments, as shown in Table 1, have been performed, and their results have been used for training and testing of the network. Randomly selected results (70\%) have been used for training, and the rest of the results (30\%) have been used for testing.

\section{RESULTS AND ANALYSIS}

In the EDM machine, the parameter will affect the machining quality on the manganese alloyed cold-work tool steel workpiece is the EDM machine parameter itself. Electrical parameter that may affect the machining quality are pulsed current and pulse time, higher or lower values of these parameters and may decrease or increased the surface integrity.

Table 1 shows the results of experimental investigation for the selected machining conditions. For various discharge currents and pulse durations, with copper electrode, following process parameter is shown: surface roughness. The results of experimental investigation, Table 1 , show a slight increase of surface roughness with the increase of pulse duration, while the discharge 
current has a more pronounced influence on surface roughness. It is evident that the discharge current defines the surface quality in EDM.

Based on experimental investigation it was established that machining quality of EDM directly depends on the machining conditions. As can be seen, the surface integrity and dimensional accuracy of EDM predominantly depend on the discharge energy but not from properties of the electrode materials. In practice, the discharge energy parameters can be changed by the discharge current and pulse duration.

Intelligent optimization techniques gives the influence of the discharge current and pulse duration on machining quality in EDM are investigated through experimental verification. The investigation results confirm the highly consent of experimental research and intelligent techniques modeling. The intelligent optimization techniques and experimental results show some good information which could be used by future researches for optimal control EDM machining conditions. This paper has successfully established neuro-fuzzy model, which consist of the pertinent process parameters, for predicting the surface finish of workpiece.

Table 1. The results of experimental investigation

\begin{tabular}{|c|c|c|c|c|c|c|}
\hline \multirow{4}{*}{$\begin{array}{c}\text { Level } \\
\left(\mathrm{N}^{\circ}\right)\end{array}$} & \multirow{2}{*}{\multicolumn{2}{|c|}{$\begin{array}{l}\text { Machining } \\
\text { conditions }\end{array}$}} & \multicolumn{4}{|c|}{ Machining characteristics of EDM } \\
\hline & & & \multirow{2}{*}{$\begin{array}{c}\text { Surface } \\
\text { Roughness } \\
\text { (Exp.) }\end{array}$} & \multicolumn{3}{|c|}{ Intelligent techniques } \\
\hline & $\begin{array}{r}\text { Discharg } \\
\text { current }\end{array}$ & $\begin{array}{c}\text { Pulse } \\
\text { duration }\end{array}$ & & ANFIS & $\begin{array}{c}\text { Neural } \\
\text { network }\end{array}$ & $\begin{array}{c}\text { Genetic } \\
\text { programming }\end{array}$ \\
\hline & $\begin{array}{c}I_{c} \\
(\mathrm{~A})\end{array}$ & $\begin{array}{c}t_{i} \\
(\mu s)\end{array}$ & $\begin{array}{c}R_{a} \\
(\mu \mathrm{m})\end{array}$ & $\begin{array}{c}R_{a F} \\
(\mu \mathrm{m})\end{array}$ & $\begin{array}{c}R_{s, N} \\
(\mu \mathrm{m})\end{array}$ & $\begin{array}{c}R_{a c} \\
(\mu \mathrm{m})\end{array}$ \\
\hline \multirow{4}{*}{$\begin{array}{l}1.1 \\
1.2 \\
1.3 \\
1.4\end{array}$} & \multirow{4}{*}{1} & 1 & 1,8 & 2,24 & 2,02 & 1,77 \\
\hline & & 2 & 1.9 & 3,09 & 2,03 & 1,86 \\
\hline & & 5 & 2,1 & 2,34 & 2,07 & 2,04 \\
\hline & & 7 & 2,3 & 2,45 & 2,11 & 2,36 \\
\hline \multirow{4}{*}{$\begin{array}{l}2.1 \\
2.2 \\
2.3 \\
2.4\end{array}$} & \multirow{4}{*}{5} & 1 & 3,9 & 4,15 & 3,92 & 4,03 \\
\hline & & 2 & 4,2 & 4,25 & 4,06 & 4,39 \\
\hline & & 5 & 5,1 & 5,08 & 4,56 & 4,88 \\
\hline & & 7 & 5,1 & 4,99 & 4,96 & 5,09 \\
\hline \multirow{4}{*}{$\begin{array}{l}3.1 \\
3.2 \\
3.3 \\
3.4\end{array}$} & \multirow{4}{*}{9} & 2 & 8,2 & 7,81 & 8,04 & 8,55 \\
\hline & & 5 & 8,8 & 8,47 & 8,40 & 8,96 \\
\hline & & 7 & 9 & 7,85 & 8,68 & 9,23 \\
\hline & & 10 & 9,8 & 9,58 & 9,14 & 9,51 \\
\hline \multirow{4}{*}{$\begin{array}{l}4.1 \\
4.2 \\
4.3 \\
4.4\end{array}$} & \multirow{4}{*}{13} & 2 & 9.2 & 9.15 & 8,84 & 8.94 \\
\hline & & 5 & 9.4 & 9.39 & 9.11 & 9.15 \\
\hline & & 7 & 9.7 & 9.54 & 9.35 & 9.43 \\
\hline & & 10 & 10,3 & 9.28 & 975 & 9.68 \\
\hline \multirow{4}{*}{$\begin{array}{l}5.1 \\
5.2 \\
5.3 \\
5.5\end{array}$} & \multirow{4}{*}{20} & 5 & 10,2 & 10,28 & 9,90 & 10,12 \\
\hline & & 7 & 10,4 & 10,40 & 10,23 & 10,48 \\
\hline & & 10 & 10,8 & 10,68 & 10,74 & 10,72 \\
\hline & & 20 & 11,2 & 10,6 & 11,95 & 11,19 \\
\hline \multirow{4}{*}{$\begin{array}{l}6.1 \\
6.2 \\
6.3 \\
6.4\end{array}$} & \multirow{4}{*}{30} & 7 & 10,8 & 10,92 & 11,68 & 11,44 \\
\hline & & 10 & 11,3 & 11,17 & 11,84 & 11,73 \\
\hline & & 20 & 11,8 & 11,79 & 12,03 & 12,15 \\
\hline & & 50 & 12,5 & 11,8 & 12,54 & 12,94 \\
\hline 7.1 & \multirow{4}{*}{50} & 10 & 11,8 & 11,80 & 12,30 & 11,81 \\
\hline 7.2 & & 20 & 12,5 & 12,49 & 12,64 & 12,21 \\
\hline 7.3 & & 50 & 13,2 & 12,5 & 13,08 & 12,79 \\
\hline 7.4 & & 100 & 13,4 & 13.40 & 13.39 & 13,60 \\
\hline \multicolumn{4}{|c|}{ Average error: } & $6,12 \%$ & $4,01 \%$ & $2,61 \%$ \\
\hline
\end{tabular}




\section{CONCLUSION}

In this paper an ANFIS, neural network (ANN) and genetic programming (GP) are used to estimate surface roughness in EDM. Figure 3 shows the compared predicted values obtained by experiment and estimated by ANFIS, ANN and GP model and show a good comparison with those obtained experimentally.

One of the most important advantages of GP of modelling is that specific equations are obtained and models can be used independently. Because of the scarcity of space and slight complexity of generated membership functions, they are not shown within this paper. They are although available on request from corresponding author.

The average error of models are checked and is found to be adequate for ANFIS model is $6,12 \%$, neural network is 4,01 and GP model is 2,61 \% confidence level and the all models can be used for predicting the surface roughness in EDM. The effectiveness of the models is only within the range and factors studies. The model adequacy can be further improved by considering more variables and ranges of parameters.

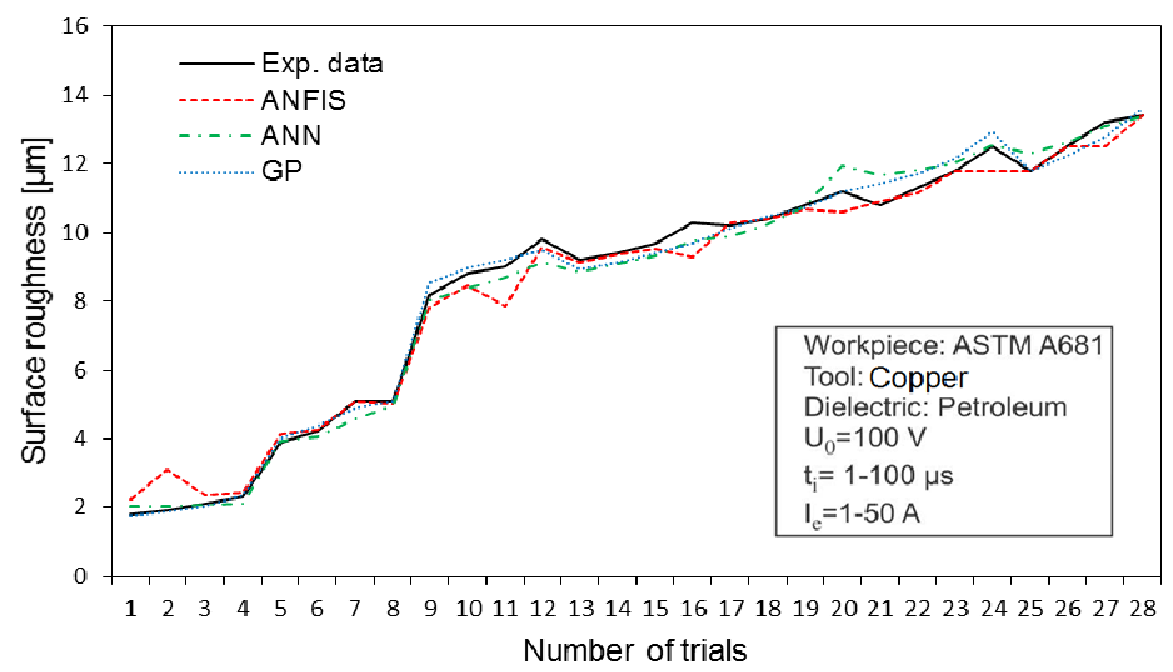

Figure 3. Correlation between experimental, ANFIS, ANN and GP surface roughness value

\section{ACKNOWLEDGEMENTS}

The paper is the result of the research within the project TR 35015 financed by the ministry of science and technological development of the republic of Serbia.

\section{REFERENCES}

[1] Chen, J. C., Savage, M. (2001) "A fuzzy-net-based multilevel in process surface roughness recognition system in milling operations" The International Journal of Advanced Manufacturing Technology, Vol. 17, pp. 670-676.

[2] Kovac, P., Rodic, D., Pucovsky, V., Savkovic, B., Gostimirovic, M. (2013). “Application of fuzzy logic and regression analysis for modeling surface roughness in face milling". Journal of Intelligent Manufacturing, Vol. 24, pp.755-762. 
[3] Radovanovic, M., Modic, M. (2010) "Methodology of neural network based modeling of machining processes" International Journal of Modern Manufacturing Technologies, Vol. 2, pp. 77-82.

[4] Norliana, M.A.; Solomon, D.G.; Bahari, M.F. (2007) "A review on current research trends in Electrical Discharge Machining (EDM)" International Journal of Machine Tools and Manufacture, Vol. 47, pp. 1214-1228.

[5] Panda, D.K.; Bhoi, R.K. (2005) "Artificial neural network prediction of material removal rate in electro discharge machining” Materials and Manufacturing Processes, Vol.20, pp. 645-672.

[6] K. Wang, H.L. Gelgele, Y. Wang, Q. Yuan, M. Fang. (2003) "A hybrid intelligent method for modelling the EDM process" International Journal of Machine Tools and Manufacture, Vol. 43, pp. 995-999.

[7] Caydas, U., Hascalık, A., Ekici, A. (2009) "An adaptive neuro-fuzzy inference system (ANFIS) model for wire-EDM” Expert Systems with Applications, Vol. 36, pp. 6135-6139.

[8] Yilmaz, O., Eyercioglu, O., Gindy, N.Z. (2006) "A user-friendly fuzzy based system for the selection of electro discharge machining process parameters" Journal of Materials Processing Technology, Vol. 172, pp. 363-371.

[9] Rao, P.S., Prasad, K.E., Reddy, B.S. (2011) "Fuzzy modelling for electrical discharge machining of aluminium alloy" International Journal of Research and Reviews in Applied Sciences, Vol. 9, pp. 112-125.

[10] Golshan, A., Gohari, S., Ayob, A. (2012) "Multi-objective optimization of electrical discharge machining of metal matrix composite $\mathrm{Al} / \mathrm{SiC}$ using non-dominated sorting genetic algorithm" International Journal of Mechatronics and Manufacturing Systems, Vol. 5, pp. 385-398.

[11] Kuriakose, S., Shunmugam, M.S. (2005) "Multi-objective optimization of wire-electro discharge machining process by Non-Dominated Sorting Genetic Algorithm" Journal of Materials Processing Technology, Vol. 170, pp. 133-141

[12] Gostimirovic, M., Kovac, P., Sekulic, M., Skoric, B., (2012). "Influence of discharge energy on machining characteristics in EDM". Journal of Mechanical Science and Technology, Vol. 26, pp.173179.

[13] Zuperl, U., Cus, F. (2003) "Optimization of Cutting Conditions During Cutting by Using Neural Networks” Robotics and Computer-Integrated Manufacturing, Vol.19, pp.189-199.

[14] GPdotNET, bhrnjica.net/gpdotnet.

[15] Tsai KM, Wang PJ (2001) "Predictions on surface finish in electrical discharge machining based upon neural network models" International Journal of Machine Tools and Manufacture, Vol. 10, pp. 13851403.

[16] Patowari, P.K., Saha, P., Mishra, P.K. (2010) "Artificial neural network model in surface modification by EDM using tungsten - copper powder metallurgy sintered electrodes"The International Journal of Advanced Manufacturing Technology Vol. 51, pp. 627-638.

\section{Authors}

MSc Dragan Rodic is a $\mathrm{PhD}$ student on the University of Novi Sad, Faculty of Technical Sciences in Serbia. He is currently research assistant at the Department of Production Engineering (2011). His research interests include advanced manufacturing cutting techniques, process modeling and artificial intelligence.

Dr Marin Gostimirovic received his B.S, M.S. and Ph.D. degrees from the University of Novi Sad, Serbia, in 1982, 1989 and 1997, respectively. He is currently a full professor at the Faculty of Technical Science at University of Novi Sad, Serbia. His research interests include advanced manufacturing - cutting techniques, non-conventional processes, heat phenomena, process modeling and artificial intelligence.

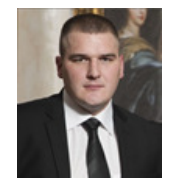

Prof. Pavel Kovac received his B.S, M.S. and Ph.D. degrees from the University of Novi Sad, Serbia, in 1975, 1980 and 1987, respectively. He is currently a full professor at the Faculty of Technical Science at University of Novi Sad, Serbia. His research interests include machining technology, metal cutting and high productive technologies, ecological systems and technologies, plastics and environment, design of experiment and artificial

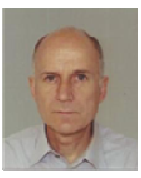
intelligence. 
Prof. Ing. Ildikó Maňková, CSc.: graduation Technical University of Kosice, Mechanical Engineering (1976), PhD thesis (1984), habilitation (1994), professor in the field of Production Engineering (2005). Her research interests include procedures and ways of process and tool condition monitoring, hard end precision machining, tool performance, application of statistical methods in measured data processing.

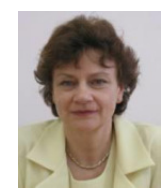

MSc Vladimir Pucovsky is a PhD student on the University of Novi Sad, Faculty of Technical Sciences in Serbia. He is currently research assistant at the Department of Production Engineering (2011). His research interests include advanced manufacturing cutting techniques, process modeling and artificial intelligence.

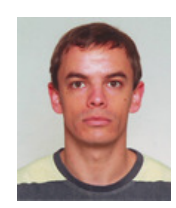

